\title{
CURBING POLLUTION
}

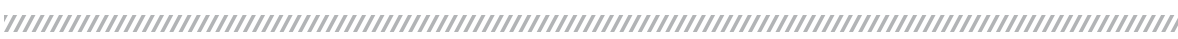

\section{Dear Readers,}

The Delhi Government's recent announcement of an experiment, wherein it plans to allow vehicles with odd and even numbers to ply on alternate days of a week, has been received with mixed reactions. While some have argued that restricting the number of vehicles on Delhi roads through a policy/ law like this is impractical, others believe the sooner people realise that they are living in a gas chamber and that they need to make drastic changes to their mindset and lifestyles, the better it would be for them and their future generations.

Pollution has come back to haunt the national capital, and this time with greater intensity. In fact, in what is considered to be the world's most definitive database of PM2.5 pollution, produced by the World Health Organisation (WHO), Delhi has been named the world's polluting city in a survey of 1,600 cities.

Some statistics are staggering, to say the least. WHO claims that outdoor air pollution kills $3.3 \mathrm{mn}$ people every year, mostly in cities. In one of its report, The Guardian of the UK stated that outdoor air pollution kills more than HIV, malaria and influenza combined.

At a recent panel discussion organised by Volvo Cars India, Dr Radha Goyal, Head, R\&D Division, Indian Pollution Control Association said $80 \mathrm{mn}$ deaths per year in Delhi are due to air pollution, caused primarily by vehicular exhausts, construction activities, re-suspension of dust and biomass burning. PM levels have crossed 700 micrograms per cubic metre in Delhi. That is nearly 12 times the permissible limit.

Coming back to the city government's move, there is no single solution to curb pollution. Imposition of such a policy/ law won't be easy, as the government would have way too many stakeholders to convince. Moreover, the whole exercise might turn out to be contrary to public interest.

The focus indeed should be on improving public transportation, essentially driven by cleaner fuels. And that needs to be done at a frantic pace. Another option the government should weigh is to impose heavy congestion charges for vehicles, particularly in areas that attract dense traffic. It is time everyone came together - leaving aside their biases - to work out measures that lead to the creation of a sustainable transportation system beneficial to all.
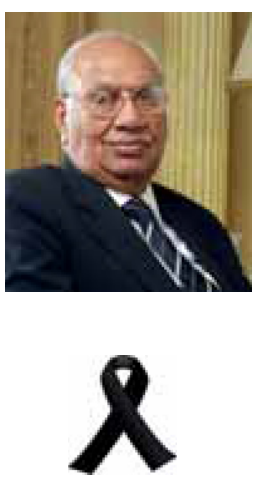

A visionary unlike anyone else, doyen of the Indian twowheeler industry and founder of the diversified Hero Group, Dr Brijmohan Lall Munjal left for his heavenly abode on November 1, 2015. A real 'Hero', he made Indian entrepreneurs and industrialists believe they could win, and win big internationally.

All of us at Auto Tech Review offer our most profound condolences on his death. May his wisdom continue to guide us all.
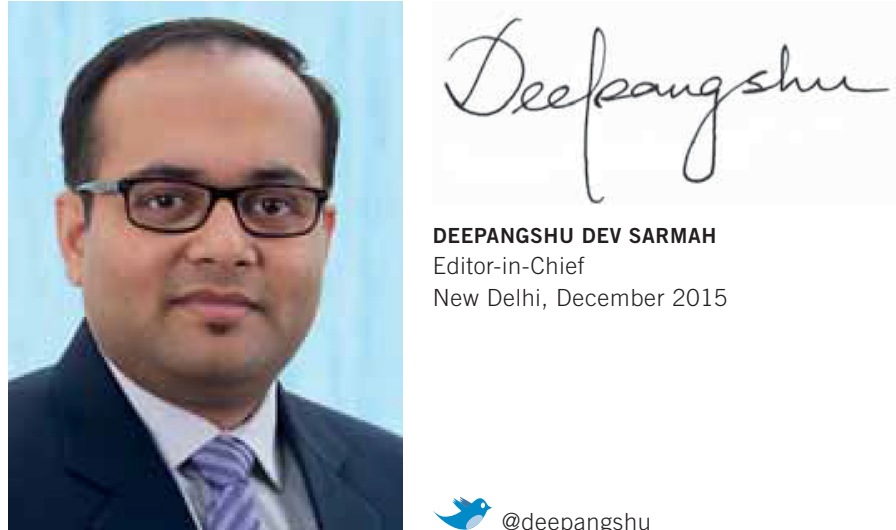

DEEPANGSHU DEV SARMAH

Editor-in-Chief

New Delhi, December 2015 